\title{
Maternidad encarcelada: análisis feminista de las consecuencias personales, familiares y sociales en mujeres privadas de libertad ${ }^{1}$
}

\author{
Paola Contreras Hernández ${ }^{2}$
}

\author{
Fecha de recepción: 27 de noviembre de 2017 \\ Fecha de aprobación: 7 de marzo de 2018
}

\begin{abstract}
Resumen
Este artículo surge de una investigación realizada en 2013, con el objetivo de explorar en las consecuencias personales, familiares y sociales que ha significado vivir (parte de) la maternidad tras las rejas de los centros penitenciarios. Se realizaron entrevistas semiestructuradas a mujeres en las cárceles de Catalunya. El análisis crítico del discurso feminista nos llevó a resultados que evidencian cómo la visión tradicional de maternidad es un factor que complejiza su devenir carcelario; sentimientos de culpa, al sentir que han fallado en su rol como madres. El aporte de este estudio gira en torno a develar la triple condena (social, familiar y penal) que enfrentan las madres encarceladas, la que se fortalece por las dinámicas internas de los centros penitenciarios.
\end{abstract}

Palabras clave: maternidad, cárcel, culpa, identidad asignada, roles de género.

\section{Imprisoned maternity: feminist analysis of personal, family and social consequences in private freedom women}

\begin{abstract}
This article is the result of a research carried out in 2013 with the aim of exploring the personal, family and social consequences that living (part of) motherhood behind bars in prison has meant. Semi structured interviews were conducted with women in prisons in Catalonia. The critical analysis of feminist discourse lead to some thought-provoking results. Significantly, how the traditional view of motherhood is a factor that complicates women's lives in prison. Feelings of guilt, self-blame can be overwhelming. The sentiment that they have failed in their role as mothers is significant. The contribution
\end{abstract}

\footnotetext{
Investigación fin de Máster en Sociología, Universidad de Barcelona.

2 Doctora en Sociología por la Universidad de Barcelona, España. Contacto: paolaontrerashz@gmail.com
} 
of this study revolves around unveiling the triple condemnation (social, family and criminal) faced by imprisoned mothers. This is strengthened by the internal dynamics in the penitentiary centers.

Keywords: Maternity, Prison, Blame, Assigned Identity, Gender Roles.

\title{
Maternidade encarcerada: análise feminista das consequências pessoais, familiares e sociais em mulheres privadas de liberdade
}

\begin{abstract}
Resumo
Este artigo surge de uma pesquisa realizada no ano 2013, com o objetivo de explorar nas consequências pessoais, familiares e sociais que tem significado viver (parte de) a maternidade atrás das grades dos centros penitenciários. Foram realizadas entrevistas semiestruturadas a mulheres nas prisões de Catalunya. A análise crítica do discurso feminista levou-nos a resultados que evidenciam como a visão tradicional de maternidade é um fator que torna mais complexa a sua vida na cadeia; sentimentos de culpa, ao sentir que têm falhado no seu papel como mães. A contribuição deste estudo gira em torno de desvelar a tripla condenação (social, familiar e penal) que enfrentam as mães encarceradas, a que se fortalece pelas dinâmicas internas dos centros penitenciários.
\end{abstract}

Palavras-chave: maternidade, prisão, culpa, identidade assignada, papéis de gênero

\section{Introducción}

Explorar en la realidad penitenciaria femenina implica aproximarse al engranaje punitivo que, mediante el aislamiento social, disciplina y domesticación, configura una compleja trama de significados, símbolos y prácticas. Este escenario se agudiza para aquellas mujeres que se ven enfrentadas a vivir su maternidad tras las rejas, pues la construcción androcéntrica de la familia define y proyecta la figura materna en función del cuidado y la crianza, absorbiendo simbólicamente la identidad de las mujeres a partir de la imagen reproductora (Frischmuth, 2009).

Este artículo explora en las consecuencias personales, familiares y sociales de mujeres que vivieron parte de su maternidad tras las rejas de los centros penitenciarios en Catalunya. Para situar este artículo, en primer lugar se presentan algunos aportes teóricos realizados por investigadoras feministas sobre la con- 
cepción patriarcal de la maternidad y sus consecuencias para las mujeres encarceladas; en segundo lugar, se exponen los aspectos metodológicos de esta investigación y se añade una breve contextualización estadística del perfil criminológico femenino en los centros penitenciarios de la Comunidad Autónoma de Cataluña. Cabe añadir que, si bien el estudio se realizó durante 2013, se actualizan las cifras penitenciarias y, por ello, se exponen tanto las de 2013 como las de 2016. Por último, en tercer lugar, se presenta el análisis de las entrevistas divido en tres partes: antes, durante y después de la cárcel. Para finalizar, se ofrecen las consideraciones finales que pretenden seguir proyectando investigaciones en esta área.

\section{Planteamientos teóricos: debates, dilemas y desafíos}

Al estudiar la maternidad como construcción simbólica, es necesario partir de la base que ésta ha sido cimentada como una categoría discursiva que refleja dinámicas de dominación/ subordinación, develando el funcionamiento social y simbólico que el patriarcado impone mediante discursos normativos, los cuales establecen una simbiosis entre identidad femenina y maternidad que sitúa la capacidad reproductora de la mujer como parte de su deber ser. En este sentido, la maternidad es entendida -desde la perspectiva androcéntrica- como una categoría ontológica que fundamenta la subjetividad femenina, legitimando la "desigualdad de género y una relación de dominación (hombremujer), inscribiéndola en una naturaleza biológica que es, en sí misma, una construcción social naturalizada (Moncó, 2009, p. 361). Las repercusiones del binomio madre-mujer se expresan a nivel simbólico (construcciones sociales sobre el modelo femenino) y material (expresadas en la división sexual del trabajo), que posicionan discursos dominantes, al establecer mecanismos de subordinación social en cuanto "verdades incuestionables" sobre el rol, figura y mandato que dirige y rige la vida de las mujeres. 
En concordancia con ello, los estereotipos de género -entendidos como categorías de identidad asignadas por la cultura (Colás Bravo, Villaciervos Moreno, 2007)- definen la maternidad como una institución propia e inherente de las mujeres. Por esta razón, los discursos que identifican a las buenas y malas madres actúan como mecanismo de control de género, en la que una buena madre debe estar en disposición total hacia sus hijos/as, es decir, una acción normativa que requiere de entrega total y absoluta (Hager, 2011). En caso contrario, cuando se trasgreden las expectativas asignadas a este rol, se genera una sanción social mediante prejuicios, clasificaciones y etiquetas que conllevan rechazo, exclusión y discriminación (Goffman, 1970; Schram, 1999). De ahí que las mujeres privadas de libertad

Están expuestas a una doble condena: la penal y la social; la primera a causa del delito cometido, y la segunda por haber infringido la normatividad del género, lo que las hace "merecedoras" de un estigma social que perdura una vez recuperada la libertad, pues cuando no se actúa en función de lo que cultural y socialmente se espera, se emplean grados de control social expresados en clasificaciones y etiquetas. (Contreras, 2016, p. 43)

Ahora bien, en el contexto carcelario tiende a ser más pujante la reproducción simbólica de: a) la maternidad como institución patriarcal; b) las diferencias de género; c) los estereotipos femeninos. Ello debido a que las mujeres sienten que han fracasado por incumplir "su papel de madres, de esposas, o incluso de abuelas, cayendo sobre ellas las culpas del sistema, antes que sobre los hombres a los que desde siempre han protegido -y en este caso, ultra-protegido- por razón de su género" (Acale Sánchez, 2011, p. 16). De esta manera, la cárcel se constituye como un "Agente discriminador [puesto que] la global atención a las necesidades de género dista mucho de haber generado alternativas y apoyos realistas a estas mujeres más allá de constituir un mantra políticamente correcto" (Mapelli Caffarena, Herrera Moreno, Sordi Stock, 2013, p. 62). 
Profundizar en la maternidad encarcelada implica, en primer lugar, comprender cómo los mecanismos de control social actúan en los imaginarios socioculturales del quehacer femenino, advirtiendo que cuando las acciones van en contra de su "natural tendencia a lo materno se las juzga y sanciona, moral y físicamente, en su detrimento. Además, no sólo son sancionadas, sino también miradas, llamadas y encasilladas severamente: la loca, la bruja, la histérica" (Palma Campos, 2011, p. 252). Y, en segundo lugar, contextualizar las dinámicas institucionales del sistema penitenciario que, bajo la insignia de la reinserción, impone un tratamiento que busca la domesticación por medio de la reproducción de los roles de género (Contreras, 2016). Desde la perspectiva feminista, analizar el funcionamiento del sistema penitenciario proporciona herramientas para hacer visible las particulares dimensiones que adquiere la violencia estatal sobre los cuerpos femeninos encarcelados.

Para Houck y Loper (2002) la maternidad es un factor que complejiza la vida de las mujeres en prisión, suscitando sentimientos de culpa, miedo y frustración, bajo la imposibilidad de mantener contacto fluido y permanente con sus hijos/as. Ello forja un inevitable desarraigo que hace más difícil la condena, teniendo un impacto negativo en la autoestima, lo que las lleva a desarrollar estados de inseguridad y baja valoración personal (Foster, 2012). Sin embargo, como contrapartida, esta situación suscita el desarrollo de estrategias para vivir su maternidad, mediante la sobreprotección a distancia y la proyección de escenarios futuros (Shamai y Kochal, 2008).

Por otro lado, desde el análisis jurídico feminista se argumenta el carácter sexista y discriminador de este espacio punitivo, cuyo marco teórico se construye sobre la base del sentido androcéntrico del derecho (Zaffaroni, 1993), el cual ha

[...] consolidado una percepción histórica de los géneros, en la cual lo masculino es un referente universal que excluye otras referencias simbolizadas por y en el géne- 
ro femenino. Esta comprensión del derecho, como enclave del patriarcado, acentúa más los aspectos externos y se intenta analizar las limitaciones de la norma jurídica desde la comprensión del papel que ésta desarrolla, es decir, a partir de su estudio en relación con el sistema político-social dentro del cual ella es generada. (Bergalli y Bodelón, 1992, p. 46)

Así, tanto el derecho como el aparato jurídico-penitenciario han establecido un modelo normativo que toma al varón como estándar de medición de conducta, constituyendo de este modo la base con la cual se mide y juzga a las mujeres (Bergalli y Bodelón, 1992), evocando ideas acerca de cómo los valores y principios nunca están desvinculados del contexto enmarcado en la cultura falocéntrica (Smart, 1994). En este ámbito, Valeije añade que:

Si en la sociedad patriarcal el control informal sobre las mujeres está fundamentalmente orientado hacia la forma en que debe desempeñar su rol de Mujer: como madre y esposa y hacia su cuerpo, en especial, hacia el ejercicio de su sexualidad, no debe causar extrañeza que esta misma orientación se haya perfilado durante años en los artículos en el texto penal. (Valeije, 1998, p. 97)

Ahora bien, la legislación penal y penitenciaria española contempla que las madres puedan estar con sus hijos/as hasta la edad de tres años; sin embargo, la normativa no atisba las consecuencias de la prisionalización en la primera etapa de infancia, como tampoco los efectos adversos de la separación. Esto ha generado que "los legisladores, la administración penitenciaria, el poder judicial y los poderes públicos en general, [se enfrenten] a cuál debe ser el tratamiento legal a esta maternidad atípica" (Igareda, 2009, p. 190). Pero la maternidad, no obstante, es vista como un tema colateral, pues lo prioritario es que las mujeres cumplan sus condenas bajo privación de libertad.

Esta realidad no ha sido lo suficientemente abordada por las ciencias sociales, pero los aportes de investigadoras feministas 
han permitido visibilizar no solo las características del sistema penitenciario femenino, sino también las discriminaciones del sistema jurídico-penal hacia las mujeres (en especial hacia las madres) y las repercusiones que ello tiene una vez recuperada su libertad, en cuanto al peso social de ser estigmatizada como delincuente y, a su vez, como mala madre. Por ello, estudiar la maternidad encarcelada significa abordar un factor importante en la vida de las mujeres; la separación y ausencia de vínculos con sus hijos/as es una de las mayores fuentes de dolor, estrechamente relacionados a los sentimientos de fracaso y culpa, que incluso persisten una vez recuperada la libertad (SURT, 2005).

Por tanto, el desafío es comenzar a profundizar en estos temas y abrir un debate en el que se pueda desmantelar los prejuicios y estereotipos que, de manera consciente o no, están presente en las relaciones sociales, y que tienden a evaluar y devaluar a todas quienes son consideradas distintas, diferentes y/o peligrosas. Abordar esta realidad nos debe permitir comprender, desde sus voces y experiencias, las consecuencias que provoca personal y familiarmente su paso por la prisión, abrir un área de investigación que profundice en ella y, a la vez, proponga alternativas que ayuden a mitigar tal situación.

\section{Breve contextualización de la población penitenciaria femenina en Cataluña, España}

Para contextualizar la investigación, se exploró en las principales características criminológicas de las mujeres recluidas, con el objetivo de observar los cambios y continuidades en la configuración de la población penal femenina; para ello se utilizaron los datos publicados por el Serveis Penitenciaris de Catalunya, del Departamento de Justicia, tanto de 2013 como de $2016^{3}$.

Como se mencionó, esta investigación se realizó el año 2013, pero incluye información estadística de 2016 para contextualizar los datos criminológicos. 
Como primer punto se destaca que desde 2013 a 2016 no ha habido mucha variación de la población penitenciaria femenina en las cárceles de Cataluña, ya que el registro histórico muestra que en 2013 el porcentaje de mujeres encarceladas (considerando las preventivas y penadas) era de un 6,56\% y en 2016 de 6,91\%. No obstante, una tendencia preocupante se observa con el colectivo de extranjeras, tanto las preventivas como condenadas, ya que si en 2013 representaban el 37,42\%, en 2016 alcanzaron el $40,5 \%$. Si bien el alza es de casi un 3\%, lo significativo es el porcentaje en ambos periodos; por su parte, las mujeres latinoamericanas alcanzan una presencia que sobrepasa el $60 \%$, tanto en 2013 como en 2016.

La propensión de delitos también muestra una variación en ambos años. Los delitos contra la propiedad pasan del 35,10 al $38,18 \%$, es decir, un aumento de un 3\%. Situación diferente se observa en los casos de homicidios, pues se mantuvo en un $9 \%$ del total. Otra variación a la baja lo representan los delitos contra la seguridad pública, disminuyendo un 4\%, pasando del 37,75 en 2013 al 33,45\% en 2016; es posible mencionar que en esta tipificación entran aquellos relacionados con las drogas (venta y tráfico). En promedio, estos tres tipos de delitos (en ambos periodos) representan más del $80 \%$ del total, lo cual permite construir los perfiles delictivos de las mujeres. Sobre los años de reclusión, las cifran indican que más del 50\% de las mujeres enfrenta condenas que van de los 3 a los 8 años.

Este es un acercamiento general al perfil delictivo femenino en Cataluña; no obstante, las limitaciones de los datos oficiales ponen de manifiesto las barreras a la hora de realizar un análisis cualitativo que recoja la complejidad y especificidad de las mujeres encarceladas. Por ello es fundamental contar con datos recogidos bajo criterios no androcéntricos, de lo contrario se seguirá reproduciendo información cargada de estereotipos o vista solo desde la perspectiva masculina, sin dar soporte real a la especificidad que las mujeres presentan. En este sentido, y una vez explorado en las estadísticas ofrecidas por el Servei Penitenciaris 
del Departamento de Justicia de Catalunya, fue muy complejo construir un perfil sociológico de la población penal femenina, ya que la información es escasa y la existente no aborda las características sociales previas a la encarcelación de las mujeres: el nivel educativo, socioeconómico, trayectorias laborales, historial de consumo o problemas toxicológicos, de salud mental, o enfermedades diversas, problemas asociados a la población extranjera, etc. Tampoco hay información del porcentaje de mujeres que son madres, cuantas tienen a sus hijos/as en el exterior, estadísticas de visita de los hijos/as y familiares, etc.

Estas limitaciones evidencian la invisibilidad de la problemática femenina, lo cual genera cuestionamientos sobre la intención real de resocializar o reinsertar a las mujeres en la sociedad una vez en libertad, ya que si la información oficial carece de profundidad, es altamente probable que tanto las políticas públicas como las investigaciones en este área puedan desarrollar diagnósticos, exploración y/o análisis mucho más completos de las características, condiciones y/o perfiles de las mujeres, y de sus necesidades y demandas.

\section{Aspectos metodológicos}

Como se indicó, esta investigación tuvo como objetivo explorar en las consecuencias personales, familiares y sociales que ha significado vivir (parte de) la maternidad tras las rejas. Para lograr dicho objetivo se utilizó el enfoque cualitativo, pues permite realizar una rigurosa descripción del colectivo estudiado, garantizando una elevada intersubjetividad en la captación de la realidad (Serrano, 1994). Se realizaron ocho entrevistas semiestructuradas, seis de las cuales fueron a mujeres que estaban recluidas en la cárcel de Wad Ras (Barcelona), las otras dos a mujeres que años anteriores estuvieron privadas de libertad en la cárcel Brians 1 (Martorell). La muestra seleccionada estuvo compuesta por cuatro mujeres nacionales (españolas) y cuatro mujeres extranjeras (dos de Marruecos, una de Argentina y otra de Brasil). 
Sus edades fluctúan entre los veinte y cincuenta años; seis con estudios universitarios y dos con educación primaria incompleta. Asimismo, seis de las participantes fueron víctimas de violencia de género. Por último, señalar que dos de las entrevistadas presentaban problemas de adicción a las drogas y son reincidentes del sistema penal-penitenciario, y que al momento de la entrevista se encontraban recluidas en la cárcel de Wad Ras.

La información fue codificada a partir tres conceptos trasversales: Maternidad, Identidades asignadas y Privación de libertad. Luego se definieron subcategorías que fueron analizadas desde el análisis crítico del discurso feminista (Lazar, 2007; Wodak y Meyer, 2001). Esta perspectiva analítica permite evidenciar las relaciones de poder y las desigualdades e injusticias que se expresan a través del habla/texto, ya que "el lenguaje no está hecho sólo de palabras, y especialmente no en tanto palabras que representen cosas ya dadas, sino que es discurso, un principio dialéctico y generativo a la vez, que remite a una red de relaciones de poder que son histórica y culturalmente específicas, construidas y, en consecuencia, susceptibles de cambio. Su estatus no es, por ello, inmanente, sino fundamentalmente político" (Colaizzi, 1990, p. 117). Este enfoque señala que los discursos son efecto/consecuencia de las relaciones sociales, y que, por tanto, proyectan un conjunto de significados políticos, sociales, culturales y personales (Van Dijk, 1999).

\section{Análisis, reflexiones del trabajo de campo}

\section{Imaginario de maternidad: aproximación a una identidad asignada}

"Ser madre fue un regalo, solo que no lo supe aprovechar".

Para indagar sobre los idearios de maternidad de las entrevistadas, abordamos en primer lugar como vivieron la maternidad antes de estar en prisión, para luego analizar hasta qué punto la propia noción de maternidad -que iban construyendo en la medida que avanzaban sus experiencias como madres- pudo ser 
uno de los eslabones que desencadenaron conflictos personales, emocionales y sociales una vez privadas de libertad.

Para algunas de las entrevistadas, la maternidad antes de prisión es un recuerdo que simboliza una etapa compleja y dificultosa, pues sus comportamientos no se adecuaban a lo que estipula la "normatividad de género" frente al binomio mujer-madre; incumplimiento que contempla procesos de discriminación. Para las participantes, la imagen materna debe ser ejemplo de bondad, amor y sacrificios, y si bien para algunas estas características eran parte de su hacer materno, el hecho de haber cometido delitos las invalidaba y devaluada como madres. Un ejemplo paradigmático de ello se observa cuando las mujeres-madres se encuentran en situaciones de consumo de drogas. Así lo manifiesta una de las participantes

Cuando tuve a mi hijo yo estaba viviendo en una casa okupa ${ }^{4}$, ahí era todo fiesta y droga y yo dejaba a mi niño durmiendo para salir a bailar y drogarme, pero después cuando llegaba no podía con el dolor y las recriminaciones de saber que pudo haber muerto (...) ninguno de los dos nos merecíamos todo esto. (Rosario, 35 años, española $\left.{ }^{5}\right)$

La condición de toxicómana inhabilita automáticamente a estas mujeres como madres y las sitúa en la categoría de malas madres, la que sin duda es asumida por las dos participantes que estuvieron relacionadas con estas prácticas de consumo, pero también por aquellas que fueron condenadas y encarceladas por trasladar drogas desde África o América a España. El relato evidencia de qué manera el consumo de drogas implica una pérdida de voluntad, autonomía y libertad en el plano personal, pero a la

Casa abandonada que es ocupada por personas con diferentes perfiles y finalidad: inmigrantes, anarquistas, activistas sociales/políticos, etc. Una práctica muy extendida en España, principalmente en Barcelona.

5 Los nombres de las mujeres entrevistadas se han cambiado para así resguardar su confidencialidad. 
vez recriminaciones al transgredir el rol social de madres, lo cual las define como desviadas. En este contexto, el estereotipo de mala madre conduce a exclusión y segregación, al ser cuestionada la idoneidad y credibilidad en el ejercicio de la maternidad.

[Cuando tuve a mi hijo] se acercó la asistente social del hospital, y al verme toda con pendientes y tatuajes, además que sabía que yo consumía droga y que no vivía con mis padres, le preguntaron a mi madre, estando yo presente, que qué iba hacer ella con mi hijo, ahí me sentí que yo no existía como madre para esa autoridad, a mí no me preguntó, era como si yo no estuviera en la sala, entendí que yo no era la madre que esperaban que fuera. (Ester, 38 años, española)

La importancia del contrato social normativo es fundamental a la hora de analizar las dinámicas sociales que se desarrollan hacia aquellas que lo han infringido; dinámicas que se orientan, por un lado, al descrédito social por ser portadoras de un atributo indeseable y, por otro, al ser identificadas como agentes peligrosas, debido a la evidente alteración de su identidad social (Goffman, 1970). En relación con esto, los estereotipos se definen cuando se infringe la imagen idealizada de lo que socialmente se entiende y acepta como madre: figura dedicada a la crianza de los hijos/ as, al cuidado y la entrega absoluta. Si esto sufre un cambio, por prácticas "desviadas" de la madre, se otorga una sanción social que se manifiesta a través del estigma que conlleva al rechazo, exclusión y discriminación, y que tiene por finalidad provocar separación o distinción negativa.

Para muchas de estas mujeres, el estigma surge por su historial de encarcelamiento, consumo de drogas, problemas de salud mental, origen étnico, orientación sexual, etc., por lo que es difícil atribuir una estigmatización particular, ya que los estereotipos tradicionales de feminidad hacen que cualquier comportamiento fuera de esta norma/imagen socialmente construida sea sancionado con una clasificación negativa. 
Explorando en los discursos de las entrevistadas respecto de lo que significa y simboliza para ellas ser madres, observamos cómo se reproducen en lo que tradicionalmente se conoce como tal:

Creo que [ser madre] es lo que te hace ser más mujer, es lo que te da el sello final y es lo más importante en la vida de una; para mí significó dejar de ser una niña y tomar el peso que tiene, ya que si lo hubiese entendido no habría tomado la decisión de traer drogas, porque eso me llevó a la cárcel y me separó de mis hijos. (Fátima, 35 años, marroquí)

Ahora bien, esta cita permite entender de qué manera las identidades asignadas -“entendidas como mecanismos de subalternidad de género [y] como dispositivos del poder jerárquico" (Nash, 2006, p. 39)- se encuentran vinculadas al triunvirato mujer-maternidad-instinto natural, el cual es concebido como un eje vector de la realización femenina que consolida la visión madre-núcleo. A partir de esta tríada, surgen cuestionamientos al sentir que han fallado en el ejercicio de la maternidad, tanto a nivel personal, como familiar y social, posicionándose en la categoría de malas madres. Esta identificación se inscribe dentro del sistema de representaciones culturales que definen las responsabilidades femeninas. En este sentido, es difícil abstraerse del ideario patriarcal de maternidad, pues la existencia de este constructo sociohistórico relega a la madre al plano de lo doméstico, privado y de cuidados. Por ello, enlazar los estereotipos femeninos con la función de madre y esposa los amalgama hasta el punto de presentarse como equivalentes, ya que "la representación cultural de la feminidad se ha basado en la dependencia, en el modelo de madre y cónyuge, devota y silenciosa, consagrada a su familia, con la reclusión escrita en el espacio doméstico" (Nash, 2006, p. 43).

Esta construcción identitaria del ser femenino facilita el desarrollo de un modelo de poder que promueve identidades/imágenes hegemónicas, estandarizadas y simplificadas, que facilitan la jerarquización social y anulan la diversidad y pluralidad de 
éstas. De esta manera, la maternidad -vista desde la edificación androcéntrica- esconde el velo de la subordinación que homogeniza el deber ser y que castiga a quienes lo incumplen.

\section{Experiencias desde la prisión: la maternidad tras las rejas}

"Ser madre y estar en la cárcel, es una doble condena".

La cárcel imprime un sesgo sexista y discriminatorio en la implementación de programas/políticas penitenciarios, situación que complejiza aún más las recriminaciones que las mujeres se autoinfieren por la desviación de sus comportamientos, que las llevaron a perder la libertad, independientemente si las acciones fueron motivadas para solventar las carencias económicas de sus familias.

En el contexto carcelario, las mujeres desarrollan procesos de resignificación de su identidad por medio de la idealización de la maternidad; sin embargo, las dinámicas propias del encierro y la desvinculación cotidiana en el cuidado de los hijos/as conlleva una confrontación entre lo real e ideal; escenario que emplaza la maternidad como un factor que agudiza sus condenas ${ }^{6}$.

En la cárcel te miran mal si eres madre, las propias mujeres y los funcionarios, te hacen sentir que eres mala y que te mereces el castigo. La mayoría somos madres, unas dicen que están aquí por los hijos; otras dicen que robaron por ellos; otras que trajeron drogas porque sus hijos no tenían que comer, y bueno están las que solo se drogaban y no quieren hablar de ellos porque quedan mal. La culpa es para todas igual. A veces los funciona-

Cabe señalar que, si bien la legislación española permite a las madres vivir con hijos/as menores de tres años en la prisión, ninguna de las mujeres entrevistadas lo hizo, lo cual se debió a que sus hijos/as no estaban en el país (para el caso de las extranjeras) y/o porque eran mayores de tres años cuando fueron encarceladas. 
rios ocupan eso y te hacen sentir peor. (Loreto, 29 años, argentina)

La cárcel es lo peor que te puede pasar si tienes hijos, ser madre y estar en la cárcel es una doble condena. Yo sabía que mi hijo sentía lástima de mí, porque sabía que era drogadicta, pero lo que más me daba impotencia era saber que la gente le decía que yo era mala con él, que nunca iba a hacer como las otras madres. (Lupe, 33 años, brasileña)

Estas palabras expresan la dureza de enfrentar la maternidad encarcelada. Ello, sumado al hecho de que la cárcel confiere estigma social y una carga simbólica potente, complejiza la situación al punto de observar una agudización de estados anímicos depresivos. Para analizar cómo se entreteje y articula el ideario patriarcal es necesario comprender cómo se interrelaciona el universo simbólico, las relaciones sociales y la subjetividad de las mujeres en estos contextos, y qué tipo de identidades y subjetividades se potencian.

Aquí la cosa es simple: debes ser una mujer lo más tranquila posible, debes estar de acuerdo con lo que te diga el consejo de tratamiento y los funcionarios, debes sentirte culpable por lo que has hecho, debes mirarte todos los días como alguien que pecó, debes decirles que estás arrepentida, aunque hayas robado para darle comida a tu familia. (Juana, 44 años, española)

Para las mujeres presas existe un patrón de comportamiento, pero si se transgrede se aplica una calificación negativa, que puede llegar a ser perjudicial en sus vidas intrapenitenciarias, al ver limitadas sus posibilidades de acceso a programas, talleres o incluso el servicio médico. Este escenario es problemático, pues si la cárcel en sí representa la exclusión por antonomasia, estar excluida dentro de ella comporta un castigo añadido.

Por tanto, la pregunta es cómo las madres asumen esta realidad y qué consecuencias ha significado para ellas y sus hijos/as, tanto en el cotidiano como en el devenir. Una de las respuestas 
viene dada por el desarrollo de estrategias de sobrevivencia que tienen como objetivo lograr la libertad y recuperar el rol que (que sienten) deben cumplir como madres.

El sistema carcelario invisibiliza el género (Carlen, 1998), en tanto no reconoce las problemáticas de las mujeres, la magnitud de los apremios que viven y el difícil abordaje que comporta resolverlos. Por ello y frente a estas limitaciones, las mujeres buscan representar los imaginarios aceptados y sobreentendidos de su ser femenino, lo que, a fin de cuentas, se traduce en un mecanismo de subalternidad desplegado como dispositivo de poder jerarquizado, que refuerza la domesticidad e identidad asignada. En este sentido, los agentes implicados en la vida penitenciaria muchas veces ponen en tela de juicio la idoneidad de las mujeres en tanto madres, por estar encarceladas y ser delincuentes, lo que genera secuelas que perduran:

A mí me cuesta aún, a pesar que llevo 5 años en la calle, sentir que estoy en lo correcto con mi hijo, trato de darle más de lo que tengo pero a veces me viene una rabia conmigo y me dan ganas de drogarme, de salir, de dejar todo, de olvidarme de mi pasado, de lo que soy, pero lucho todos los días por sentir que soy distinta, a veces me siento falsa, quiero que la gente me mire de una manera distinta, no quiero volver a sentir esas risas que se burlan de ti y recordar al custodio [gendarme] que me grita lo perversa que soy como madre. (María, 46 años, española)

Precisamente, este testimonio evidencia las consecuencias que experimentan las mujeres que son madres y que pueden llegar a determinar sus comportamientos en el entorno familiar y social, pero sobre todo en la autopercepción y actitud personal, poniendo en tela de juicio lo que las conforma en tanto mujeres / hijas/madres/esposas; autocastigarse es una respuesta al sentir que son el factor que complejiza y debilita la dinámica familiar; que son las causantes de las dificultades que enfrentan sus hijos/ 
as, pues, como dijo una entrevistada: "Cárcel no se borra, queda en tu vida".

De este modo, las secuelas que conlleva la separación son múltiples y diversas, tanto para las madres como para sus hijos / as. El sostenimiento económico y cuidado recae muchas veces en una responsabilidad exclusiva de la madre, situación que las lleva a asumir el delito como estrategia de supervivencia familiar. La cárcel termina siendo la consecuencia final de estas acciones, y de manera directa implica que el cuidado de los hijos/ as se vea envuelto en una confusa relación entre las familias e instituciones sociales que buscan resguardar "el bien mayor de los menores". La institucionalización es una respuesta a la mala "gestión" como madres, pues han descuidado a sus hijos/as. Ello imprime -directa o indirectamente- el estigma de ser hijo/a de una delincuente, lo que acentúa la exclusión social. Asimismo y bajo la impronta de prevalecer el cuidado y estabilidad de el/la menor, se restringe el contacto entre madre e hijo/a, limitando las visitas (si es que no se excluyen de forma absoluta) a los centros penitenciarios; por tanto, el vínculo se debilita y se abren nuevas grietas en la vida de ambos: afectivas, emocionales, personales y sociales.

Por otra parte y considerando la construcción social que existe en torno a la figura de la madre, la denostación personal y social actúa como un factor que altera los estados de ánimo e incluso puede llevar a las mujeres a desajustes psicológicos severos. El maltrato de las instituciones, las constantes recriminaciones personales y familiares y la nula o escasa proyección fuera de la cárcel -por la inexistencia de programas sociales- se articulan como una intersección que permite analizar de qué manera las opresiones patriarcales sobre las madres "desviadas" acentúan distintos niveles y grados de violencias y que repercuten en la seguridad personal, que limitan las posibilidades sociales y laborales una vez recuperada la libertad, que establecen una distancia o debilitan el vínculo afectivo con sus hijos/as, que imprimen 
un estigma que difícilmente podrán eliminar y que las sitúa en dinámicas de exclusión social.

\section{La maternidad después de la prisión}

"Yo tenía ganas de empezar todo de nuevo, de conocer nuevas personas, de trabajar y volver a vivir".

En este último apartado presentaremos -de manera generalcómo estas mujeres han vivido su maternidad una vez recuperada su libertad. En el caso de las entrevistas realizadas en la cárcel de Wad Ras, es importante señalar que dos de las participantes son reincidentes, por lo que sus discursos tienden a confluir en los periodos de libertad y prisión.

En las narrativas se logra entrever cómo el estigma de (la) delincuente toma peso a la hora de retomar sus vidas fuera de la cárcel, siendo necesario recuperar la seguridad para comenzar la reinserción social; proceso que está marcado por innumerables obstáculos y constantes desafíos personales y familiares. Sin caer en un análisis homogeneizador de las mujeres y madres que han estado privadas de libertad, en tanto causas y efectos, existe un elemento que se repite en las narraciones de las participantes al momento de hablar de reinserción social: la confianza y seguridad se presentan como un binomio esencial para comenzar a reconstruir las redes familiares, sociales, personales y laborales.

La primera vez que salí con permiso, mis padres me dejaron sola en casa, y tenía miedo de abrir los cajones de los muebles porque no quería que ellos pensaran que les había robado algo, tenía miedo que pensaran que había tomado sus cosas, así que no me moví del sofá en toda la tarde, estaba paralizada. Sabía que tenía que reconstruir la confianza perdida y eso fue lo más difícil de todo, porque yo tenía ganas de empezar todo de nuevo, de conocer nuevas personas, de trabajar y volver a vivir. (María, 46 años, española) 
La reinserción en este periodo es fundamental para comenzar a desarrollar procesos de autoconfianza; sin embargo, para las mujeres extranjeras esto es complejo. Así lo señala una de las participantes:

Cuando salí, no sabía bien qué hacer, tenía miedo de que la policía me pidiera los papeles y que se dieran cuenta que había estado en la cárcel y por eso me deportaran, luego pensaba cómo ganarme la vida, quería darle a mis hijos más de lo que tenía, pero a una mujer como yo, que estuvo presa ¿quién le va a dar trabajo?, si ahora ni para limpiar te cogen. Además que aquí la gente piensa que porque eres musulmana y extranjera les vas a robar. Si piensan eso por no ser de aquí, ¿tú crees que no lo van a pensar si además estuve en la cárcel? (Amina, 32 años, marroquí)

La situación para las mujeres extranjeras resulta doblemente difícil. La sobrerrepresentación en las cárceles catalanas y del Estado español en general evidencia que existe una realidad penitenciaria diferenciada entre nacionales (autóctonas españolas) y extranjeras. Para las segundas, la separación, soledad, falta de vínculos directos con la familia y entorno social, el racismo y la discriminación actúan como factores que dificultan la vida intra y extrapenitenciaria. Es importante añadir que las extranjeras no reciben visitas ni apoyos económicos, como sí sucede con las nacionales, siendo habitual que tengan menos probabilidades de lograr acceder al régimen abierto o disfrutar de permisos de salidas, ya que dos de los requisitos para ello es el arraigo familiar y opciones u ofertas laborales. Por ello, consideramos que existen múltiples discriminaciones por el hecho de ser mujer y extranjera, a lo que se debe añadir indudablemente la discriminación por ser madre.

De igual modo, es necesario indicar que si las presas en general están invisibilizadas en el debate público, político y social, las extranjeras prácticamente no existen, sus problemáticas son diferentes; por ejemplo, para aquellas que no hablan el idioma español 
la situación es aún más difícil y limitante, demostrando la falta de garantías que agravan su cotidiano devenir penitenciario.

Según el Departamento de Justicia de Catalunya, "en todos los sistemas penales europeos se dan dos datos constantes en relación con la población extranjera: por un lado, se le aplica más prisión preventiva que en la población nacional, y por otro, se le aplican menos medidas penales alternativas. Pero, hay que decir que lo que marca la diferencia a la hora de explicar estas tendencias no son las variables de perfil criminológico ni personal, sino las variables legales asociadas a la condición de extranjero y las variables sociales propias de la falta de disponibilidad de medios propios o de apoyo externo"(Circular 1/2011, p. 3).

El desarraigo social y la ausencia de pertenencias identitarias acompañan a las mujeres extranjeras en sus vidas intrapenitenciarias, a lo que se debe sumar, una vez recuperada la libertad, el miedo a que -producto de las políticas migratorias del país- puedan ser deportadas al país de procedencia. Para las mujeres extranjeras es justamente en este periodo cuando los problemas se complejizan y se presentan como un enjambre político, social, personal y familiar que obstaculiza proyectos de vida, generación de recursos económicos, asociatividad, etc., y que indudablemente se profundiza al estar lejos de sus hijos/ as y familias.

Ahora bien, la trama a la cual se enfrentan las madres una vez recuperada la libertad es compleja, pero a la vez diferenciada, pues para las nacionales (españolas) el proceso puede resultar menos traumático que para las extranjeras, ya que cuentan con un soporte familiar que actúa como un factor que permite desarrollar estabilidad en distintos ámbitos de sus vidas, sobre todo en la reconstrucción de puentes comunicantes hacia y con sus hijos/as; sin embargo, para las extranjeras la distancia, soledad y casi inexistencia de vínculos sociales hace que el escenario sea más problemático. Aquí es importante indicar que un porcentaje muy significativo de extranjeras encarceladas lo está por el tras- 
lado de drogas (lo cual hace que se las apode como "mulas"), situación que permite entender que muchas llegan a España sin tener redes familiares o sociales.

Pero para ambas (nacionales y extranjeras) los prejuicios y discriminaciones operan como un motor que aumenta la exclusión social y que repercute en las posibilidades de construir nuevas opciones de vida, pues, como indica una de las entrevistadas, "la sociedad no perdona" y el estigma perdura y la prisión no se borra.

\section{Consideraciones finales}

Esta investigación reflejó cómo la maternidad es una construcción sociocultural que lleva a las madres privadas de libertad a mirarse desde un prisma negativo, al sentir que no cumplieron con las responsabilidades que implica el rol de madre. La existencia de un conjunto de significados naturalizados socialmente provoca discriminación genérica para quienes no los cumplen, enfrentando una sanción estigmatizadora que las identifica con el modelo de mala madre. Esta representación es una asignación imaginaria/simbólica que busca identificar lo femenino con lo maternal y que absorbe como un todo la vida de las mujeres. De ahí se comprende por qué la maternidad es un factor que complejiza la vida de las mujeres que se encuentran privadas de libertad, pues la internalización de esta imagen materna implica asumir estereotipos negativos por haber desatendido sus obligaciones.

En este aspecto, las contribuciones académicas han evidenciado hasta qué punto las instituciones penitenciarias refuerzan los estereotipos de género que operan como mecanismo de control para disciplinar en torno a la homogeneidad y domesticidad femenina. Justamente, la criminología feminista ha cuestionado estas dinámicas porque empeoran la cotidianidad carcelaria de las mujeres, especialmente de quienes son madres; además porque reproducen patrones de subordinación desde principios androcéntricos, que imposibilitan la reflexividad de las propias 
mujeres hacia un mejor vivir, ya sea en su presente como en su futuro, ya sea como mujeres o madres.

Por último, cabe añadir que este estudio busca contribuir a un diálogo que permita seguir explorando, analizando y generando evidencias sobre los múltiples matices, especificidades, cambios y continuidades del complejo entramado en el cual se ven envueltas las identidades, cuerpos y emociones de las mujeres; sobre todo de aquellas que, por diferentes motivos, han tomado rutas fuera de la normatividad de género y que las ha llevado a ser sancionadas, estereotipadas y estigmatizas, ya sea antes, durante y después de su paso por la prisión.

\section{Referencias}

Acale Sánchez, M. (2011). Mujeres, crímenes y castigo. [Versión electrónica]. Hachetetepé, 2, 13-32.

Bergalli, R. y Bodelón, E. (1992). La cuestión de las mujeres y el derecho penal Simbólico. [Versión electrónica]. Anuario de Filosofía del Derecho, 9, 43-73.

Colaizzi, G. (1990). Feminismo y teoría del discurso: razones para un debate. En G. Colaizzi (ed.), Feminismo y teoría del discurso (pp. 108-123). Madrid: Cátedra.

Carlen, P. (1998). Women's Imprisonment: A Study in Social Control. London: Editorial Routledge \& Kegan Paul.

Colás Bravo, P. y Villaciervos Moreno, P. (2007). La interiorización de los estereotipos de género en jóvenes y adolescentes. [Versión electrónica]. Revista de Investigación Educativa, 25, 35-58.

Contreras, P. (2016). Maternidad tras las rejas: Una aproximación a la realidad de las mujeres en las cárceles de Catalunya (España). Revista Umbral, 11, 39-58.

Foster, H. (2012). The strains of maternal imprisonment: Importation and deprivation stressors for women and children. [Versión electrónica]. Journal of Criminal Justice, 3, 221-229.

Frischmuth, S. (2009). La maternidad en el pensamiento feminista occidental. [Versión electrónica]. Revista Artículos y Ensayos de Sociología Rural, 7, 45-56. 
Goffman, E. (1970). Estigma: la identidad deteriorada. Buenos Aires: Ediciones Amorrortu.

Hager, T. (2011). Making Sense of an Untold Story: A Personal Deconstruction of the Myth of Motherhood. [Versión electrónica]. Qualitative Inquiry, 17, 35-44.

Houck, K., Loper, A. B. (2002): The relationship of parenting stress to adjustment among mothers in prison. [Versión electrónica]. American Journal of Orthopsychiatry, 72, 548-558.

Igareda, N. (2009). La maternidad de las mujeres presas. En I. Rivera Beiras y R. Bergalli (coord.), Género y dominación: críticas feministas del derecho y el poder (pp. 159-194). Barcelona: Editorial Anthropos.

Lazar, M. (2007). Feminist critical discourse analysis: articulating a feminist discourse praxis. Critical Discourse Studies, 4, 141164.

Mapelli Caffarena, B., Herrera Moreno, M. y Sordi Stock, B. (2013). La Exclusión de las Excluidas. ¿Atiende el sistema penitenciario a las necesidades de género?: Una visión andaluza. [Versión electrónica]. Estudios Penales y Criminológicos, 33,59-95

Moncó, B. (2009). Maternidad ritualizada: Un análisis desde la antropología de género [Versión electrónica]. AIBR, Revista de Antropología Iberoamericana, 4, 357-384.

Nash, M. (2006). Identidades de género, mecanismos de subalternidad y procesos de emancipación femenina. [Versión electrónica]. CIDOB d'afers internacionals, 73, 39-57.

Palma Campos, C. (2011). Delito y sobrevivencia: las mujeres que ingresan a la cárcel El Buen Pastor en Costa Rica por el tráfico de drogas. [Versión electrónica]. Anuario de Estudios Centroamericanos, 37, 245-270.

Schram, P. (1999). An exploratory study: stereotypes about mothers in prison. [Versión electrónica]. Journal of Criminal Justice, 27, 411-426.

Serrano Pérez, G. (1994). Investigación cualitativa II: retos e interrogantes: técnicas y análisis de datos. Madrid: Editorial La Muralla.

Shamai, M. \& Kochal, R. (2008). Motherhood Starts in Prison: The Experience of Motherhood Among Women in Prison. [Versión electrónica]. Family process, 3, 323-340. 
Smart, C. (1994). La mujer del discurso jurídico. En E. Larrauri (coord.), Mujeres, derecho penal y criminología (pp.167-177). Madrid: Ediciones Siglo XXI.

SURT. (2005). Mujeres, Integración, y Prisión. Barcelona: Ediciones Áurea.

Valeije, I. (1998). La mujer y el derecho penal. [Versión electrónica]. Asparkía, 9, 19-27,

Van Dijk, T. (1999). Ideología: Una aproximación multidisciplinar. Barcelona: Editorial Gedisa.

Wodak, R. \& Meyer, M. (2001). Methods of critical discourse analysis. London: SAGE Publicactions.

Zaffaroni, R. (1993). La mujer y el poder punitivo. Costa Rica: Editorial ILANUD. 